\section{International Journal \\ of \\ English Studies}

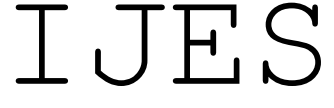

http://revistas.um.es/ijes

\title{
Study of accuracy and grammatical complexity in EFL writing
}

\author{
ANA CRISTINA LAHUERTA* \\ Universidad de Oviedo (Spain)
}

Received: 16/05/2016. Accepted: 19/05/2017.

\begin{abstract}
The aim of the present study is to compare the writing products of English as a Foreign Language (EFL) university students using accuracy and grammatical complexity as measures. It also aims at examining the development of the morphological, syntactic, lexical, spelling, and punctuation errors committed by these learners when writing in English. Students enrolled in a University Degree in Modern Languages and their Literatures participated in the study. They were divided into advanced and upper intermediate according to their Oxford Placement Test score. Compositions were collected as the basis of this study. Results show that upper intermediate students exhibited a higher error mean in each of the error categories, namely, grammatical morphemes, lexical choice and syntax, as well as punctuation and spelling. However, an analysis of variance shows the differences between groups to be significant only in spelling and punctuation errors.
\end{abstract}

KEYWORDS: writing, accuracy, grammatical complexity, errors, university.

\section{INTRODUCTION}

Larsen-Freeman (2006) understands language as a complex, dynamic system and language use/acquisition as dynamic adaptedness to a specific context. This, in her own words (2006: 590) "proves a useful way of understanding change in progress, such as that which occurs with a developing L2 system". As Larsen-Freeman states, because language is complex, progress cannot be totally accounted for by performance in any subsystem. She refers to van Geert and Steenbeek (2005) to explain that linguistic subsystems, dimensions of language proficiency (accuracy, fluency, and complexity), and even individual elements of language interact in ways that could be both supportive and competitive. This perspective sees

*Address for correspondence: Ana Cristina Lahuerta. University of Oviedo, Department of English, French and German, Oviedo, Spain; e-mail: lahuerta@uniovi.es. 
"linguistic signs not as autonomous objects of any kind, either social or psychological, but as contextualised products of the integration of various activities by [particular] individuals in particular communicative situations" (Larsen-Freeman, 2006: 594).

Written competence is a subset of learners' language competence, with an emphasis on writing-specific abilities such as the production of a variety of genres and rhetorical features, but also including language-specific abilities like the use of a range of vocabulary and syntactic structures (Wolfe-Quintero, Inagaki \& Kim, 1998: 2). Written competence as a subset of language competence is also complex and can only be explained by the interaction of different dimensions of language proficiency. Moreover, fluctuations in one component, such as fluency or complexity, might be associated with various fluctuations in another (Skehan, 1998, 2009).

As our framework for the present study, the notions of complexity, accuracy, and fluency which make up the Common Assessment Framework (CAF) are regarded as the principal constructs to capture the multidimensionality of L2 written performance. Within this framework we intend to examine two dimensions of written language proficiency, namely, grammatical complexity and accuracy, considering the relationships and interactions between them. Moreover, the aim is to study and analyse the errors in the written English of EFL learners as an indicator of their developmental stage in morphology, syntax and lexis. This study examines learners at two levels of proficiency, upper intermediate (B2) and advanced (C1) users according to the Common European Framework of Reference (CEFR) for Languages (Council of Europe, 2001).

\section{REVIEW OF THE LITERATURE}

Foster and Skehan (1996: 303-304) defined accuracy as "freedom from errors" and development in grammatical complexity as "progressively more elaborate language" and a "greater variety of syntactic patterning". These authors argue that complexity connects with change and the opportunities for development and growth in the interlanguage system whereas accuracy concerns control at a particular interlanguage level.

One approach to the study of second language writing accuracy is the analysis of how many errors occur in relation to production units such as words, clauses, or T-units (e.g. Bardovi-Harlig \& Bofman, 1989; Homburg, 1984; Kuiken \& Vedder, 2008). Another approach is to examine whether a structural unit of some type is error-free, whether clauses, sentences or T-units (e.g. Tedick, 1990). Other research works focus on specific error categories such as collocations (e.g. Barfield, 2007; Laufer \& Waldman, 2011) and a number of other errors (e.g. Chan, 2010; Dipolog-Ubanan, 2016). Studies like Thewissen (2012, 
2013) investigate second language accuracy developmental patterns by means of the study and interpretation of errors of an EFL learner corpus. These studies will be reviewed in some detail below.

Homburg (1984) classified errors into three categories according to their effect on comprehensibility (from errors that did not interfere with comprehension to errors that made interpretation almost impossible): first-degree errors, second-degree errors, and third-degree errors. He found that second-degree errors per T-unit, and error-free T-units per composition differentiated among the three proficiency levels studied. More recently, Kuiken and Vedder (2008) using a similar approach, which identified first-, second- and third-degree errors based on their effect on communication also reported statistically significant differences between the first- and second-degree errors per T-unit across all levels of task complexity.

Bardovi-Harlig and Bofman (1989) examined the relationship between syntactic complexity and overall accuracy in the written English of two groups of advanced adult foreign language learners divided according to their performance on a placement test. Syntactic complexity, measured in number of clauses per T-unit, was found to be similar in all groups. The analysis of errors revealed that these advanced foreign language learners showed similar patterns of error distribution. In addition, they all showed relative strength in syntax, but relative weakness in morphology.

In a study on English as a Second language (ESL) graduates' writing performance, Tedick (1990) identified significant differences among students at different proficiency levels for holistic score and for accuracy. Specifically, the intermediate and advanced groups were significantly different from the beginning group with regard to global scores and number of error-free T-units.

Thewissen (2013) investigated second language accuracy development in learner essays extracted from an EFL learner corpus. The data pointed to different types of development for the EFL groups across the B1 to C2 continuum: progress-only errors, stabilisation-only errors, progress and stabilisation errors, and error types with marked regression. Progress and stabilisation trends were the dominating EFL patterns and progress was often located between B1 and B2.

The identification of specific error categories has been the goal of a number of studies. For example, Chan (2010) identified grammatical and syntactic errors in the writing of university and secondary education Cantonese ESL learners. Grammatical problems included misuse of conjunctions and prepositions. Errors from the syntactic level consist of incorrect word order (incorrect ordering of adverbials), missing constituents (omission of subjects), and subordination errors like misuse of relative clauses and independent clauses as subjects. More recently, Dipolog-Ubanan (2016) investigated the common errors in the paragraphs written by EFL Chinese undergraduates. The results showed that the most common errors were on word choice and word form, spelling, tenses, use of articles and determiners, number 
and agreement of subject and verb. Barfield (2007) and Laufer and Waldman (2011) explored the use of collocations by L2 learners. Barfield (2007) found that Japanese learners of English reported better knowledge of single nouns and verbs than they did of combinations of the same nouns and verbs into collocations. Laufer and Waldman (2011) reported that native speakers of Hebrew at three proficiency levels produced far fewer English verb-noun collocations than native speakers did. They also concluded that "the number of collocations increased only at the advanced level, and that errors continued to persist even at advanced levels of proficiency" (2011: 647).

Grammatical complexity measures include two types of measures. The first type are those which analyse the clauses, sentences or T-units in terms of each other (e.g., clauses per sentence, dependent clauses per T-unit, T-units per sentence, etc.). The second type refers to measures that explore the presence of specific grammatical structures in relation to clauses, T-units or sentences (e.g., passives per sentence, complex nominals per T-unit, coordinate clauses per T-unit, connectors per sentence) (Wolfe-Quintero et al., 1998: 69-99). The studies below use measures of fluency, accuracy and complexity to examine writing performance.

The longitudinal analysis of the written production of five Chinese learners of English, using measures of fluency, accuracy and grammatical a lexical complexity by LarsenFreeman (2006) showed that over a six-month period, participants were writing more fluently and accurately, and their writing had become more complex in grammar and vocabulary. However, there was a difference between group and individual performances: group performance was characterised by a relatively linear development, whereas some individual performances regressed and progressed, and others did not change over time. Besides, the rate of change varied for different participants at different times.

Nicolás-Conesa, Roca de Larios and Coyle (2014) analysed writers' internal process factors by examining the longitudinal development of undergraduate EFL students' stored beliefs on the task and goals and their contribution to the development of L2 written performance. Participants wrote two argumentative essays on the same topic initially before starting their writing instruction and then nine months later. Learners' essays were analysed from a dual perspective: using holistic rating and analytical measures, namely, complexity, accuracy and fluency. Findings showed that the participants improved their written performance over time. Nonetheless, this improvement was evident only in the holistic rating. No significant changes were found over time in any of the measures analysed, that is, accuracy, fluency or complexity. As the authors conclude: "The results provided empirical evidence of high written performance and improvement in written scores across time on the part of students who define the task in terms of problem-solving processes, self-evaluate positively their writing achievement, and have the desire of continuing to improve by pursuing new goals for writing" (2014: 15). 
Knoch, Rouhshad and Storch (2014) studied the development of students' ESL writing proficiency after a year's study in an Australian university. The study dealt with writing development using global writing scores, as well as measures of accuracy, fluency, grammatical and lexical complexity. The results of the study showed that global scores of writing did not change over time. The only significant improvement participants revealed was in their fluency (measured via text length). That is, they could write longer texts in the time allowed. There were no observed gains in accuracy, syntactic and lexical complexity (2014: 8-10).

Consistent with Knoch et al. (2014), Knoch, Rouhshad, Oon and Storch (2015), who examined undergraduate students' L2 (ESL) writing proficiency following a three-year degree study in an L2-medium university, using global and measures of accuracy, fluency, complexity, showed that global scores of writing did not improve significantly over the three years of degree study. In terms of the discourse measures, also consistent with Knoch et al. (2014), fluency (measured via word count) increased significantly over three years of degree study, indicating that participants were able to produce more words within the same allotted time, whereas accuracy, grammatical and lexical complexity did not change over time (Knoch et al., 2015: 50).

Godfrey and Treacy (2014) examined the writing of eight university learners of French - four during study abroad and four in on-campus courses-over the course of a semester using measures of complexity, accuracy, fluency. Results showed that progress toward more advanced academic L2 writing occurred for both groups of students, although in different ways. For example, students in both groups improved their fluency in writing, as measured by length of their essays, but the domestic group seemed to increase essay length more than the study abroad group did. A T-unit analysis demonstrated that, while both groups increased the syntactic complexity in their writing, the domestic group improved more than the study abroad group did.

Within the analysis of the grammatical complexity of EFL/ESL writers, a series of studies focus on cohesive devices in compositions. Comparisons between essays written by native speakers of English and Swedish EFL students (Altenberg \& Tapper, 1998), and between native speakers of English and Japanese EFL learners (Narita, Sato \& Sugiura, 2004) showed that students used fewer connectors in their writing than the native speakers, and they tended to overuse and underuse certain types of connectors.

Wei-yu Chen (2006), who carried out a corpus-based connector study on the writing of master students in Taiwan found out that causal conjunctions were used inappropriately by some of the learners. Likewise, Hamed (2014), who investigated the use of conjunctions in argumentative essays written by fourth-year undergraduate Libyan students majoring in English, found out that the students used the conjunctions inappropriately, and that the adversative conjunctions posed the greatest difficulty for the learners, followed by additives 
and causals. Lahuerta (2016) analysed the use of conjunctions by Spanish EFL learners in their expository writings. The participants were third-year and fourth-year secondary education enrolled on a bilingual and a non-bilingual programme. Results of the quantitative analysis reflected a positive significant relationship between conjunction density and the composition global score, both in the bilingual and the non-bilingual group. The qualitative analysis revealed little variety in the participants' use of conjunctions, especially among nonbilingual and third-grade students. The study showed that participants experienced difficulty in using conjunctions, especially adversative and additive ones.

\section{STUDY}

The review of the literature above uncovers conflicting results. Whereas some studies on L2 writing report significant differences among proficiency levels and gradual improvement in holistic scores and in accuracy, grammatical and lexical complexity (e.g. Larsen-Freeman, 2006; Tedick, 1990), a number of studies fail to show such an improvement (e.g., Knoch et al., 2014, 2015; Nicolás-Conesa et al., 2014). Contrasting results are also obtained in error development: whereas some studies found out a linear error development (e.g. BardoviHarlig \& Bofman, 1989; Larsen-Freeman, 2006), others like Thewissen (2013) showed a nonlinear evolution of errors.

In view of these conflicting findings, we intend to shed some light on the two unsolved questions in the literature, namely whether and how L2 written competence as measured by accuracy and complexity develops as proficiency increases, and the question of the evolution of errors, that is, the pattern of error development. Moreover, as we have seen in the literature reviewed above, a number of studies have examined specific error categories. The findings of these studies will be taken into account in our own analysis of the participants' compositions. The informants of the present study are upper-intermediate and advanced undergraduates, two competence levels which have received little attention in the literature. Thus, the aim of the present study is twofold: (a) it seeks to examine and compare the compositions of EFL undergraduates at two levels of L2 proficiency using accuracy and grammatical complexity as measures; and (b) it describes the evolution of the morphological, syntactic, lexical, spelling and punctuation errors, as English is used by both groups of learners. Early SLA researchers such as Brown and Fraser (1964) and Corder (1967) argued that errors are a useful tool into the analysis of the processes of second language acquisition, acting as the best evidence of the developmental stages learners are likely to have reached. This article will examine learners' errors in order to capture their developmental trajectories.

Our research questions are the following: 
1. Is there a significant difference in writing between both levels (upper intermediate and advanced) in every measure used?

2. Which level makes more errors of each type? Is there a difference between both levels in the kind of errors committed? Which error categories and subcategories decrease significantly in the levels?

\subsection{Subjects}

Participants were two groups of Spanish EFL learners. They were undergraduate students enrolled in the Degree in Modern Languages and their Literatures at a University in the North of Spain. They were divided into two groups according to their Oxford Placement Test score: group A was formed by 34 students with a score between 150 and 169 (advanced or $\mathrm{C} 1$ as per the CEFR); and group B was made up of 66 students with a score between 135 and 149 (upper intermediate or B2 as per the CEFR). This test, which includes a grammar and a listening section, was used in this study to place the participants in the appropriate level according to the Common European Framework of Reference for Languages as a prior step to the research study.

\subsection{Procedure}

Data were elicited from intact class groups in an exam-like situation. The instrument used to obtain the data was a composition on one of three topics: "Discuss the growing popularity of audio books", "There should be no legal retirement age", "First-world societies suffer from an obsessive dependence on technological gadgets". They were asked to write between 300 and 350 words. We gathered a total of 31.900 words.

\subsection{Data analysis}

The students' essays were scored along the following parameters: grammatical complexity, accuracy and surface errors. We define accuracy as the absence of deviations from a particular linguistic norm or the absence of errors. Our study focuses on grammatical, syntactic and lexical errors. Nevertheless, spelling and punctuation errors are also given prominence in the present study since the scarce research on these error types seem to show strong association of them with certain proficiency levels (e.g. Thewissen, 2012, 2013, 2015), which calls for further research. Our approach to the analysis of accuracy is twofold. On the other hand, it is based on whether a structural unit is error-free and, on the other hand, it is concerned with the study and analysis of the errors made by the learners in their written production. Thus, as we can see in Table 1 below, for accuracy, the measure used was error- 
free sentence ratio. Regarding the grammatical complexity measures, we used sentence complexity ratio, connector ratio, and passive ratio in the writing samples. We considered that higher incidence of connectors and passive would indicate a greater control over the syntactic structure of the language and over coordination and subordination.

\begin{tabular}{|l|l|}
\hline CONSTRUCT & MEASURES \\
\hline \multirow{4}{*}{ Grammatical complexity } & $\begin{array}{l}\text { Sentence complexity ratio } \\
\text { Total number of sentences/Total number of clauses }\end{array}$ \\
\cline { 2 - 2 } & $\begin{array}{l}\text { Connector ratio } \\
\text { Total number of connectors/Total number of words }\end{array}$ \\
\cline { 2 - 2 } & $\begin{array}{l}\text { Passive ratio } \\
\text { Total number of passives/Total number of words }\end{array}$ \\
\hline Accuracy & $\begin{array}{l}\text { Error-free sentence ratio } \\
\text { Total number of error-free sentences/Total number of sentences. }\end{array}$ \\
\hline
\end{tabular}

Table 1. Accuracy and complexity measures.

In order to classify the errors into the corresponding category, we followed BardoviHarlig and Bofman's (1989: 21) classification and definition of each error type and subtype. Errors were analysed and scored as syntactic, morphological or lexical. Syntactic errors consisted of errors of word order, errors resulting from the absence of constituents, and errors in combining sentences. Word-order errors included errors in the order of major constituents (such as pragmatically unacceptable deviations from SVO) and minor constituents (such as adverb placement). Deletion of a major constituent (subject, verb or object), and sentence fragments that lacked finite verbs also fell into this category. The last type of syntactic error was errors in sentence combining, that is, errors in complementation, relativisation or coordination. Morphological errors comprised errors in nominal morphology (plural, number agreement, uncountable nouns and compounds), errors in verbal morphology (tense, subjectverb agreement and passive formation), errors in determiners and articles, errors in prepositions and errors in derivational morphology (e.g. lack of suffixes, etc.). We also included errors in connectors in this category. As lexical errors, we counted lexical-idiomatic or vocabulary errors. We also examined spelling errors and errors that targeted punctuation problems, that is, confusion between punctuation markers, missing or redundant markers.

For the analysis, the essays were divided into sentence and clausal units in Microsoft Excel sheets. Then they were manually analysed and annotated for the different types of errors studied. All essays were analysed, annotated and counted by one researcher who was a native speaker of Spanish and were checked by a second researcher that was a native speaker of English. As instances of error cases that caused disagreement, we can mention errors that involved the confusion between a punctuation marker and a conjunction of coordination or vice versa, and the overuse of sentence connectors such as sentence-initial "then". When these discrepancies occurred, they were discussed among the researchers until an agreement was reached. The percentage of agreement was higher than $95 \%$. Errors of each type at each 
level of proficiency were counted in relation to the total number of words in the learner's composition.

\section{RESULTS}

A statistical analysis was carried out with the program R (R Core Team, 2012), 2.15 version.

There were significant differences between advanced and upper intermediate students both in complexity and in accuracy (see Table 2 below). Group A (advanced students) outscored Group B (upper intermediate students) in grammatical complexity as measured by the total number of sentences per clause $(M=41.87$, Student's t-test, $\mathrm{p}<0.05)$. This group also outperformed Group B in accuracy as measured by error-free sentences ( $M=47.51$, Student's t-test, $\mathrm{p}<0.05)$. When complexity is measured by the total number of connectors per words and by the total number of passives per words, we can observe that the mean score of group A is higher than that of group B but no significant difference is obtained between the two groups $(M=3.86 ; M=0.99$, Student's t-test, $\mathrm{p}>0.05)$. This result could be due to the type of task carried out. The participants had to write an expository text on a number of topics that may not have stimulated the use of passive sentences. This result calls for more research studies with different types of text to clarify this question.

\begin{tabular}{|l|l|r|r|r|}
\hline & \multicolumn{1}{|c|}{ Group } & \multicolumn{1}{c|}{ Mean } & \multicolumn{1}{c|}{ SD } & \multicolumn{1}{c|}{ P } \\
\hline \multirow{2}{*}{ Sentence complexity ratio } & Group A & 41.87 & 40.22 & $\mathbf{0 . 0 4}$ \\
\cline { 2 - 5 } & Group B & 37.42 & 36.68 & \\
\hline \multirow{2}{*}{ Error-free sentence ratio } & Group A & 47.51 & 47.22 & $\mathbf{0 . 0 1}$ \\
\cline { 2 - 5 } & Group B & 24.25 & 21.01 & \\
\hline \multirow{2}{*}{ Connector ratio } & Group A & 3.86 & 3.08 & 0.54 n.s. \\
\cline { 2 - 5 } & Group B & 3.20 & 3.09 & \\
\hline \multirow{2}{*}{ Passive ratio } & Group A & 0.99 & 0.98 & 0.39 n.s. \\
\cline { 2 - 5 } & Group B & 0.81 & 0.66 & \\
\hline
\end{tabular}

Table 2. Advanced and upper intermediate students' written competence as measured by accuracy and complexity measures.

As seen in Table 3, error mean for all of the error types displays a tendency toward improvement from B2 to $\mathrm{C} 1$. Nevertheless, the statistical analysis reflects the differences between groups to be significant only in spelling errors $(M=0.45 ; M=0.26$, Student's t-test, $\mathrm{p}<0.05)$, and in punctuation errors $(\mathrm{M}=0.61 ; \mathrm{M}=0.24$, Student's t-test, $\mathrm{p}<0.05)$. These error categories show a positive developmental trend as there is statistically significant difference between the upper intermediate and advanced levels.

We observe a similar distribution of errors for both groups with the largest percentage of errors found in morphology, followed by lexis and finally syntax. Punctuation and spelling errors are the least frequent in both advanced and upper intermediate students' writings. 


\begin{tabular}{|c|c|c|c|c|}
\hline & Group & Mean & SD & $\mathbf{P}$ \\
\hline \multirow[t]{2}{*}{ Syntactic errors ratio } & Group A & 0.62 & 0.37 & \\
\hline & Group B & 1.65 & 1.22 & $0.10 \mathrm{n} . \mathrm{s}$ \\
\hline \multirow[t]{2}{*}{ Morphological error ratio } & Group A & 1.58 & 1.43 & \\
\hline & Group B & 3.83 & 2.31 & $0.17 \mathrm{n} . \mathrm{s}$ \\
\hline \multirow[t]{2}{*}{ Lexical error ratio } & Group A & 0.94 & 0.94 & \\
\hline & Group B & 2.47 & 1.12 & 0.29 n.s \\
\hline \multirow[t]{2}{*}{ Spelling error ratio } & Group A & 0.26 & 0.30 & \\
\hline & Group B & 0.45 & 0.31 & 0.04 \\
\hline \multirow[t]{2}{*}{ Punctuation error ratio } & Group A & 0.24 & 0.01 & \\
\hline & Group B & 0.61 & 0.31 & 0.04 \\
\hline
\end{tabular}

Table 3. Distribution of errors for advanced and upper intermediate students.

Table 4 reports the distribution of error types within the category of grammatical morphemes. The number and percentage of students with at least an error of each type was calculated. As we can observe, the number of errors tend to decrease as proficiency level becomes higher. There are nevertheless three error types with a higher percentage in Group A. One of them is among the most frequent errors within the morphological category in both groups: tense misuse. Incorrect use of no article showed no sign of improvement across the B2-C1 performance range. Examples 1, 2, 3 and 4 (extracted from the participants' writing) exemplify the inappropriate use of the article.

(1) In this essay I will deal with the intricate issue of the $\$ 0 \$$ retirement.

(2) It is not always fun to listen to the $\$ 0 \$$ audio books but it depends on the person who speaks.

(3) I am going to talk about addiction to the $\$ 0 \$$ technological gadgets and their impact on the $\$ 0 \$$ health.

(4) This essay is an attempt to analyse one of the major controversial issues in the $\$ 0 \$$ first-world societies: the dependence on technological devices.

The literature agrees that articles present varying levels of difficulty depending on the learners' proficiency level as well as their L1 background (e.g. Larsen-Freeman, 1983). In Spanish, the use of an article is compulsory and this appears to explain why some English uses remain a problematic area for our participants.

Errors in prepositions and connectors remain weak areas, even for the advanced group. It is worth noting that the percentage of each of these errors is quite high. Within tense, errors in modal auxiliaries also remain a weak area for both groups, which may be understandable in view of the complexity of English modal verb use. The following sample sentences from our participants' compositions serve to illustrate the inappropriate use of tense (examples 5 and 6), modals (7 and 8) and prepositions (9 and 10). 


\begin{tabular}{|c|c|c|}
\hline & Group B (B2) & Group A (C1) \\
\hline & Error percentage & Error percentage \\
\hline \multicolumn{3}{|l|}{ Nominal morphology } \\
\hline Plural & 17.18 & 13.88 \\
\hline Number agreement, uncountable nouns and compounds & 65.63 & 44.44 \\
\hline \multicolumn{3}{|l|}{ Verbal morphology } \\
\hline \multicolumn{3}{|l|}{ Subject-verb agreement } \\
\hline -s omitted & 4.69 & 5.55 \\
\hline -s overgeneralised & 28.13 & 2.77 \\
\hline \multicolumn{3}{|l|}{ Tense } \\
\hline Ill-formed & 7.81 & 5.55 \\
\hline misuse & 68.75 & 69.44 \\
\hline Passives & 6.25 & 5.55 \\
\hline Connectors & 60.94 & 44.44 \\
\hline \multicolumn{3}{|l|}{ Articles } \\
\hline Incorrect article & 7.81 & 8.33 \\
\hline No article & 100.00 & 100.00 \\
\hline Unnecessary article & 45.31 & 25.00 \\
\hline \multicolumn{3}{|l|}{ Determiners } \\
\hline Incorrect determiners & 59.38 & 22.22 \\
\hline No determiner & 15.63 & 11.11 \\
\hline Unnecessary determiner & 17.19 & 13.88 \\
\hline \multicolumn{3}{|l|}{ Prepositions } \\
\hline Incorrect preposition & 67.19 & 63.88 \\
\hline No preposition & 15.62 & 5.55 \\
\hline Unnecessary preposition & 17.18 & 8.33 \\
\hline Derivational morphology & 21.88 & 2.77 \\
\hline
\end{tabular}

Table 4. Distribution of errors in grammatical morphemes by percentage of occurrence for groups A and B (advanced and upper intermediate students).

(5) Many people will give up their job when they will feel \$feel\$ stressed or tired.

(6) The dependency of people on technological gadgets reached \$has reached\$ a high level nowadays.

(7) In my opinion, people must not \$should not\$ use some technological gadgets so often.

(8) In the past people must \$had to \$ choose from a smaller selection of possibilities.

(9) There has been a rise of \$in\$ the number of people being diagnosed with so-called 'lifestyle diseases' such as depression and Obsessive Compulsive Disorder.

(10) In some cases an employer can retire in \$at $\$$ a certain age although they must give a reason.

(C) Servicio de Publicaciones. Universidad de Murcia. All rights reserved. IJES, vol. 18 (1), 2018, pp. 71-89 Print ISSN: 1578-7044; Online ISSN: 1989-6131 
Frequent errors committed by our students were the use of connectors with no justification in the previous sentence or paragraph. There were also instances of missing connectors to join sentences or paragraphs. A common mistake was the redundant use of two connectors together (e.g. "but however"; "however even"). When we focused on the use of specific connectors, we found that numerous instances of "and" were used inappropriately in the learners' writing. For example, sometimes the discourse unit introduced by "and" just repeated another sentence in the same paragraph and the connector failed to add new information. Example 11 from the participants' corpus reflects this inappropriate use of and.

(11) We must use technological devices when we need them. However, if we use them in a continuous fashion, they me lose their usefulness. *And technological gadgets are good sometimes although you have to know when to use them and when not to use them.

The proper use of the connector "so" to express a causal relation also presented problems to the participants. As the use of "so" was examined, it was found that the participants used the conjunction "so" even though there was no causal relationship between the units linked by the connector. Examples 12 and 13 extracted from the participants' corpus show this inappropriate use of "so".

(12) The government should do its best to punish law violators. *So, the government should increase the fine for law breaking.

(13) This addictive behaviour should be avoided. *So people are responsible for not using these gadgets so often.

Similarly, the participants used the conjunction "on the other hand" even though there was no contrasting relationship between the units linked by the connector. This can be observed in the following example from the participants' corpus.

(14) The more we use technological devices, the more dependent we will become, so we should try to avoid this dependency. *On the other hand, I would like to say that we should be in favour of the internet.

When we analysed single connector choice we found that learners tended to use a limited set of connectors ("and", "but", "on the other hand", "because", "so", "for example", and "such as" are the most frequent ones) which they repeated over and over again.

Table 5 offers the distribution of syntactic errors for both groups. Group A presents a lower percentage of each type of syntactic errors with two exceptions: word order and 
relative clauses. In the following examples from the corpus we observe the use of an -ing form instead of a relative clause and the incorrect use of a relative pronoun.

(15) Such programs as the technology awareness programmes that arise an interest in learning and knowing about the new technologies or even showing \$that show\$ people how to take advantage of such technologies.

(16) Some measures and laws, that \$which\$ defend people's rights, are now being taken in some European countries.

Example 17 and 18 from the corpus show instances of incorrect word order.

(17) One could see how diversified is this group \$this group is\$.

(18) We should try to see the boundaries in order to not create \$in order not to create\$ an abusive society.

The distribution of syntactic error types is similar for both groups. Errors in complementation followed by word order and sentence fragments are the most frequent errors in both groups. As we can observe, some of these errors have a high error percentage at both levels of proficiency. For example, the error percentage of complementation is 60.93 at $\mathrm{B} 2$ vs 47.22 at $\mathrm{C} 1$, and that of word order is 53.22 at B2 vs 59.37 at $\mathrm{C} 1$.

\begin{tabular}{|l|r|r|}
\hline & \multicolumn{1}{|c|}{ Group B (B2) } & Group A (C1) \\
\hline & Error percentage & Error percentage \\
\hline Word order & 53.22 & 59.37 \\
\hline Complements & 60.93 & 47.22 \\
\hline Relative clauses & 7.81 & 13.88 \\
\hline Coordination & 10.93 & 8.33 \\
\hline Fragments & 40.62 & 22.22 \\
\hline Missing constituents & 23.43 & 16.66 \\
\hline
\end{tabular}

Table 5. Distribution of syntactic errors by percentage of occurrence for groups A and $B$ advanced and upper intermediate students.

Tables 6 and 7 present the mean percentage of morphological and syntactic errors. Differences between groups were statistically significant only in four morphological errors types: -s generalised $(\mathrm{M}=0.11 ; \mathrm{M}=0.01$; Student's t-test, $\mathrm{p}<0.05)$, use of incorrect determiners $(M=0.32 ; M=0.10$; Student's t-test, $\mathrm{p}<0.05)$, use of no determiner $(\mathrm{M}=0.35$; $\mathrm{M}=0.16$; Student's t-test, $\mathrm{p}<0.05)$, and derivational morphology $(\mathrm{M}=0.08 ; \mathrm{M}=0.01$; Student's t-test, $\mathrm{p}<0.05)$. These error categories revealed significant progress between B2 and $\mathrm{C} 1$. The number of these errors steadily and significantly decreases as proficiency increases. 


\begin{tabular}{|c|c|c|c|c|c|}
\hline & \multicolumn{2}{|c|}{ Mean } & \multicolumn{2}{|c|}{ SD } & \multirow[b]{2}{*}{$\boldsymbol{P}$} \\
\hline & $\begin{array}{c}\text { Group } A \\
(C 1)\end{array}$ & $\begin{array}{c}\text { Group B } \\
(\text { B2) }\end{array}$ & $\begin{array}{c}\text { Group } A \\
(\text { C1 })\end{array}$ & $\begin{array}{c}\text { Group B } \\
(\text { (B2) }\end{array}$ & \\
\hline \multicolumn{6}{|l|}{ Nominal morphology } \\
\hline Plural & 0.05 & 0.08 & 0.00 & 0.00 & 0.18 \\
\hline Number agreement and possessive & 0.27 & 0.52 & 0.29 & 0.25 & 0.45 \\
\hline \multicolumn{6}{|l|}{ Verbal morphology } \\
\hline \multicolumn{6}{|l|}{ Subject-verb agreement } \\
\hline -s omitted & 0.03 & 0.01 & 0.00 & 0.00 & 0.83 \\
\hline -s overgeneralised & 0.01 & 0.11 & 0.00 & 0.00 & 0.01 \\
\hline \multicolumn{6}{|l|}{ Tense } \\
\hline Ill-formed & 0.05 & 0.02 & 0.00 & 0.00 & 0.34 \\
\hline misuse & 0.24 & 0.60 & 0.00 & 0.32 & 0.44 \\
\hline Passives & 0.02 & 0.02 & 0.00 & 0.00 & 0.7 \\
\hline Connectors & 0.21 & 0.46 & 0.00 & 0.29 & 0.15 \\
\hline \multicolumn{6}{|l|}{ Articles } \\
\hline Incorrect article & 0.05 & 0.05 & 0.00 & 0.00 & 0.94 \\
\hline No article & 0.06 & 0.19 & 0.00 & 0.00 & 0.35 \\
\hline Unnecessary article & 0.10 & 0.32 & 0.00 & 0.00 & 0.2 \\
\hline \multicolumn{6}{|l|}{ Determiners } \\
\hline Incorrect determiners & 0.10 & 0.32 & 0.00 & 0.30 & $\mathbf{0 . 0 1}$ \\
\hline No determiner & 0.16 & 0.35 & 0.00 & 0.00 & $\mathbf{0 . 0 1}$ \\
\hline Unnecessary determiner & 0.06 & 0.16 & 0.00 & 0.00 & 0.36 \\
\hline \multicolumn{6}{|l|}{ Prepositions } \\
\hline Incorrect preposition & 0.33 & 0.56 & 0.30 & 0.30 & 0.46 \\
\hline No preposition & 0.03 & 0.04 & 0.00 & 0.00 & 0.56 \\
\hline Unnecessary preposition & 0.03 & 0.07 & 0.00 & 0.00 & 0.1 \\
\hline Derivational morphology & 0.01 & 0.09 & 0.00 & 0.00 & 0.01 \\
\hline
\end{tabular}

Table 6. Morphological error mean percentage of Groups A and B (advanced and upper intermediate students).

\begin{tabular}{|l|r|r|r|r|r|}
\hline & \multicolumn{2}{|c|}{ Mean } & \multicolumn{2}{c|}{ SD } & \multirow{2}{*}{ P } \\
\cline { 1 - 5 } & $\begin{array}{c}\text { Group A } \\
(\text { C1 })\end{array}$ & $\begin{array}{c}\text { Group B } \\
(\text { B2 })\end{array}$ & $\begin{array}{c}\text { Group A } \\
(\text { C1 })\end{array}$ & $\begin{array}{c}\text { Group B } \\
(\text { B2 })\end{array}$ & \\
\hline Word order & 0.09 & 0.15 & 0.00 & 0.00 & 0.06 \\
\hline Complements & 0.25 & 0.72 & 0.00 & 0.32 & 0.12 \\
\hline Relative clauses & 0.05 & 0.05 & 0.00 & 0.00 & 0.82 \\
\hline Coordination & 0.02 & 0.02 & 0.00 & 0.00 & 0.76 \\
\hline Fragments & 0.15 & 0.37 & 0.00 & 0.00 & 0.14 \\
\hline Missing constituents & 0.06 & 0.11 & 0.00 & 0.00 & 0.3 \\
\hline
\end{tabular}

Table 7. Syntactic error mean percentage of Groups A and B (advanced and upper intermediate students). 


\section{DISCUSSION}

The present study has contributed to a better understanding of the development of upperintermediate and advanced undergraduates' written competence. More specifically in response to our first research question this study presents a clear improvement pattern from $\mathrm{B} 2$ to $\mathrm{C} 1$ in written competence. We found a significant difference in written competence between the two groups examined, with the advanced group of learners being better in complexity and accuracy indicators. These results clarify previous inconclusive findings, and support previous research (e.g. Godfrey \& Treacy, 2014; Larsen-Freeman, 2006).

The present work also contributes to clarify the question of the development of the different dimensions of L2 writing competence examined. One of the most outstanding findings in this respect is that the writing development of the upper intermediate and advanced EFL groups investigated, although characterised on the whole by progress, also presents some cases of stabilisation tendencies and regression although the latter very rarely featuring in our data. However, we do not regard these tendencies as always indicating absence of learning. As Larsen-Freeman (2006: 597) states, stabilisation is not "linguistic rigor mortis". In other words, the stabilisation tendency should not be narrowly interpreted as an absence of any development whatsoever. Regarding regression, it may in fact at times be explained by increasing levels of complexity, especially at the more advanced levels. In that case, as learners move beyond the upper intermediate stage, they may take more risks, which results in more errors. In certain cases, then, there may be an inverse relationship between complexity and accuracy as learners continue to develop in their writing. Studies like Polio and Shea (2014) suggest that in assessing writing development, accuracy should be considered in combination with complexity.

The present study also contributes to earlier findings regarding the stage of development of morphology and syntax in advanced learners. Thus, in line with BardoviHarlig and Bofman's (1989) findings, our students show relative strength in syntax. Not only are more errors evidenced in grammatical morphemes, but their use on the part of the learners also shows greater variability, as demonstrated by the highest standard deviations of the five error types both in Group A and Group B.

With respect to error development (our second research question), although we might expect an increase in proficiency level to go hand in hand with a decrease in errors or improvement in accuracy, the evidence is that only four of the error categories indicate a statistically significant developmental trend. Grammatical morphemes such as articles, prepositions, verb tenses, connectors and syntactic categories like subordination and word order remain problematic areas for these upper intermediate and advanced students.

These results do tally with previous findings. For example, Larsen-Freeman (1983) found the majority of errors to occur in the three categories of articles, prepositions and verb tense across five levels of proficiency. With respect to tense usage, previous studies on tenses 
(e.g. Hawkins \& Buttery, 2010; Thewissen, 2013) conclude that tenses remain a weak area, even for more advanced groups. Dipolog-Ubanan (2016) highlighted that the most common errors in the writing of EFL undergraduates were tenses, use of articles and determiners. Studies like Hamed (2014), Lahuerta (2016) and Wei-yu Chen (2006) maintained that EFL learners have difficulty in using conjunctions in their writing. Concerning syntax, misuse of relative clauses is identified as a common error type in prior studies (e.g. Chan, 2010; Thewissen, 2013).

Finally, the present study also examined errors in important L2 areas such as punctuation and spelling, all of which have received scarce developmental attention to date. Unlike previous research studies that present punctuation errors as improvement-resistant features across proficiency levels (e.g. Thewissen, 2013), our study reveals that these error categories diminish as proficiency increases. It also contradicts findings that punctuation errors are more frequent at upper intermediate levels of proficiency (Thewissen, 2015). In the case of spelling, our study confirms previous findings (e.g. Thewissen, 2013) showing that spelling errors significantly decrease by the time learners reach an upper intermediate level.

\section{CONCLUSIONS}

This study presented a number of findings which are encouraging on the whole as progress was the dominant tendency among the learners being studied. At the same time, this study also revealed weaknesses and variability in the development of morphology and syntax at the higher levels of proficiency. Our findings have some implications for L2 writing pedagogy. Our study has demonstrated the importance of some measures of linguistic complexity and accuracy that should be of interest to teachers concerned with identifying weak developmental points in their students. Awareness of and attention to these findings can help L2 teachers understand those areas not adequately developed in writing that may need more emphasis by means of adequate activities and writing tasks. In addition, in our view, it is necessary to adopt a methodology that follows a discourse point of view when approaching a writing task. For instance, some of the errors found in our corpus related to the inappropriate use of modal verbs. The meaning expressed by modality may spread over stretches of discourse. This makes it more difficult for learners not to make mistakes, especially if they are taught a sentence-based approach to modal auxiliary verb usage. The following example shows the importance of selecting a discourse instead of a sentence point of view to avoid the repeated erroneous uses of "would" after the first one.

Everybody wishes to possess technological gadgets. This would \$will\$ involve the beginning of a dependence on technology. But would \$will\$ it be possible to depend on technology and at the same time be free and independent? 
Writing activities following this approach could be analytical activities in which learners examine how writers use certain lexical or grammatical items or how they form sentences in authentic texts and they reflect on the consequences that the writer's grammatical, syntactic and lexical choices have for the surrounding text. Another activity could focus on searching for errors within a large text and providing learners with clear and simple meta-linguistic explanation, that is, an explanation of rules with some examples that illustrate the targeted feature. Learners could also be given a short text and be asked to list the phrases related to some lexical field present in the text. They would have to search the data and identify a particular pattern and the language forms associated with it. With all these activity proposals, teachers provide learners with activities that encourage them to observe, analyse and think about samples of discourse and to draw their own conclusions about how written language works.

Finally, this work has analysed accuracy and complexity development at the higher levels of proficiency, and in this way we have contributed to a better knowledge of competence levels, which, as Ortega and Byrnes (2008: 4) have argued are "currently underresearched".

\section{REFERENCES}

Altenberg, B. \& Tapper, M. (1998). The use of adverbial connectors in advanced Swedish learners' written English. In S. Granger (Ed.), Learner English on Computer (pp. 80-93). Harlow: Addison Wesley Longman Limited.

Bardovi-Harlig, K. \& Bofman, T. (1989). Attainment of syntactic and morphological accuracy by advanced language learners. Studies in Second Language Acquisition, 11, 17-34.

Barfield, A. (2007). An exploration of second language collocation knowledge and development. Unpublished Doctoral Dissertation, University of Swansea, United Kingdom.

Brown, R. W. \& Fraser, C. (1964). The Acquisition of Syntax. In U. Bellugi \& R. Brown (Eds.), The Acquisition of Language. Monograph of the Society for Research in Child Development (pp. 43-79). New York, NY.

Chan, A.Y.W. (2010). Toward a taxonomy of written errors: Investigation into the written errors of Hong Kong Cantonese ESL learners. TESOL Quarterly, 44(2), 295-319.

Corder, S. P. (1967). The significance of learners' errors. International Review of Applied Linguistics in Language Teaching, 4, 161-179.

Council of Europe. (2001). Common European Framework of Reference for Languages: Learning, Teaching, Assessment. Cambridge: Cambridge University Press.

Dipolog-Ubanan, G. (2016). L1 influence on writing in L2 among UCSI Chinese students: A case study. Pertanika Journal of Social Sciences and Humanities, 24(4), 1835-1847.

Foster, P. \& Skehan, P. (1996). The influence of planning and task type on second language performance. Studies in Second Language Acquisition, 18, 299-323.

Godfrey, L. \& Treacy, C. (2014). Change in French second language writing in study abroad and domestic contexts. Foreign Language Annals, 47(1), 48-65. 
Hamed, M. (2014). Conjunctions in argumentative writing of Libyan tertiary students. English Language Teaching, 7(3), 108-120.

Hawkins, J. \& Buttery, P. (2010). Criterial features in learner corpora: Theory and illustrations. English Profile Journal, 1, 1-23.

Homburg, T.J. (1984). Holistic evaluation of ESL compositions: Can it be validated objectively? TESOL Quarterly, 18(1), 87-107.

Knoch, U., Rouhshad, A. \& Storch, N. (2014). Does the writing of undergraduate ESL students develop after one year of study in an English-medium university? Assessing Writing, 21, 1-17.

Knoch, U., Rouhshad, A., Oon, S. P. \& Storch, N. (2015). What happens to ESL students' writing after three years of study at an English medium university? Journal of Second Language Writing, 28, 39-52.

Kuiken, F. \& Vedder, I. (2008). Cognitive task complexity and written output in Italian and French as a foreign language. Journal of Second Language Writing, 17, 48-60.

Lahuerta Martínez, A. (2016). Uso de las conjunciones en las composiciones de estudiantes de programas bilingües y no bilingües. Revista de Educación, 371, 107-125.

Larsen-Freeman, D. (1983). Assessing global second language proficiency. In H. W. Seliger \& M. H. Long (Eds.), Classroom Oriented Research (pp. 287-304). Rowley, MA: Newbury House.

Larsen-Freeman, D. (2006). The emergence of complexity, fluency, and accuracy in the oral and written production of five Chinese learners of English. Applied Linguistics, 27(4), 590-619.

Laufer, B. \& Waldman, T. (2011). Verb-noun collocations in second language writing: A Corpus analysis of learners' English. Language Learning, 61(2), 647-672.

Narita, M., Sato, C. \& Sugiura, M. (2004). Connector usage in the English essay writing of Japanese EFL Learners. Paper presented at the Fourth International Conference on Language Resources and Evaluation, Portugal, May, 26-28.

Nicolás-Conesa, F., Roca de Larios J. \& Coyle, Y. (2014). Development of EFL students' mental models of writing and their effects on performance. Journal of Second Language Writing, 24, $1-19$.

Ortega, L. \& Byrnes, H. (Eds.). (2008). The Longitudinal Study of Advanced L2 Capacities. New York \& London: Routledge.

Polio, C. \& Shea, M.C. (2014). An investigation into current measures of linguistic accuracy in second language writing research. Journal of Second Language Writing, 26, 10-27.

R Core Team (2012). R: A language and environment for statistical computing, Vienna, Austria. http://www.R-project.org/.

Skehan, P. (1998). A Cognitive Approach to Language Learning. Oxford: Oxford University Press.

Skehan, P. (2009). Modelling second language performance: Integrating complexity, accuracy, fluency, and lexis. Applied Linguistics, 30, 510-532.

Tedick, D. J. (1990). ESL writing assessment: Subject-matter knowledge and its impact on performance. Studies in Second Language Acquisition, 9, 123-143.

Thewissen, J. (2012). Accuracy across proficiency levels: insights from an error-tagged EFL learner corpus. Unpublished Doctoral Dissertation, Université Catholique de Louvain, Louvain-laNeuve, Belgium.

(C) Servicio de Publicaciones. Universidad de Murcia. All rights reserved. IJES, vol. 18 (1), 2018, pp. 71-89 Print ISSN: 1578-7044; Online ISSN: 1989-6131 
Thewissen, J. (2013). Capturing L2 accuracy developmental patterns: Insights from an error-tagged EFL learner corpus. The Modern Language Journal, 97, 77-101.

Thewissen, J. (2015). Accuracy across Proficiency Levels: A Learner Corpus Approach (Corpora and Language in Use). Belgium: UCL Press.

Van Geert, P. \& Steenbeek, H. (2005). A complexity and dynamic systems approach to development assessment, modelling and research. In K. W. Fischer, A. Battro \& P. Lena (Eds.), Mind, Brain, and Education. Cambridge: Cambridge University Press.

Wei-yu Chen, C. (2006). The use of conjunctive adverbials in the academic papers of advanced Taiwanese EFL learners. International Journal of Corpus Linguistics, 11(1), 113-130.

Wolfe-Quintero, K., Inagaki, S. \& Kim, H. (1998). Second Language Development in Writing: Measures of Fluency, Accuracy, and Complexity. Hawai'i: University of Hawai'i at Manoa. 